\title{
FINANÇAS
}

\section{Caverna global}

uso disseminado de tecnologias eletrônicas de informação
edetelecomunicação gerou umaintensa conectividadeentre
mercados, empresas e economias nacionais. Como resultado, crises desenroladas em uma parte do planeta são imediatamente transferidas, por contágio, às outras partes da rede formada por esses agentes econômicos. 0 artigo analisa as origens desse contágio e seus principais efeitos sobre países, empresas e indivíduos.

por William Eid Junior FGV-EAESP

O escritor português José Saramago, recentemente celebrizado pela premiação com o N obel de literatura, usou uma interessante metáfora para referir-se à nossa época. Para o autor, vivemos em uma grande caverna, assim como nossos ancestrais viviam. No entanto, com uma pequena diferença: a caverna, hoje, refere-se ao próprio mundo. Com essa metáfora, Saramago chama a nossa atenção para uma das principais conseqüências do uso das novas tecnologias eletrônicas de distribuição de informação e de telecomunicação - a conectividade entre países, indivíduos e, como veremos neste artigo, economias nacionais.

Em finanças, a conectividade vem se tornando um fenômeno popular, sobretudo em momentos de crise ou de euforia dos mercados financeiros. Q uando isso ocorre, 
os meios de comunicação de massa, por exemplo, são os primeiros a apresentar as conseqüências em cascata da crise sobre bolsas de valores, índices de preço, variação do dólar e sobre o bolso do consumidor.

Neste artigo, analisamos, em primeiro lugar, os efeitos gerais da conectividade de acordo com seu impacto sobre três registros econômicos importantes: 0 das empresas, dos indivíduos e, principalmente, o de mercados financeiros. Em segundo lugar, o artigo anal isa especificamente o fenômeno denominado pelos especialistas como contágio, situação em que o comportamento de um mercado ou país afeta automaticamente o comportamento dos mercados de outros países. 0 artigo discute, por fim, as conseqüências desse efeito-contágio sobre as economias nacionais, as empresas e os indivíduos.

Empresas e mercados. A conectividade trouxe progressos significativos em comparação ao que era possível em décadas anteriores para empresas, indivíduos e mercados. Por exemplo, as empresas podem realizar hoje consultas, cobranças, pagamentos, saques e transferências em tempo real. O u seja, podem realizar negócios à velocidade das correntes elétricas ou das ondas de rádio - um sinal emitido na Tailândia, via satélite, leva menos de um segundo para chegar a São Paulo! ágil do que no passado, obrigando seus participantes a acompanharem as inovações de perto, abrindo um leque imenso de oportunidades. Tome-se, por exemplo, a rapidez e facilidade com que uma empresa pode oferecer seu produto em qualquer parte do mundo. Estudos do Banco Mundial mostram que os exportadores de países em desenvolvimento que têm acesso à Internet apresentam resultados superiores aos de exportadores sem esse tipo de acesso.

Em acréscimo, os controles nas empresas também podem se beneficiar dessa crescente velocidade: um problema que antes só era identificado depois que suas conseqüências tivessem causado danos fatais pode ser hoje corrigido quase ao mesmo tempo em que ocorre. Tal situação pode ser encontrada principalmente naquelas empresas que possuem operações espalhadas em grandes áreas ou mesmo em diversos países.

No entanto, é certamentenos mercados financeiros que observamos o maior impacto da conectividade. Um investidor pode aplicar seus recursos em praticamente qualquer parte do mundo, a qualquer momento. Além disso, a conectividade trouxe um subproduto interessante: a padronização dos mercados. De acordo com isso, as regras nos mercados financeiros são muito parecidas, o que permite a existência de investimentos além das fronteiras nacionais.

Outra conseqüência importante

\section{Entre os países emergentes, o Brasil é o que} mais sofre em períodos pós-crises em virtude

\section{da el evada liquidez dos títulos da dívida}

\section{pública do país no mercado internacional.}

éa possibilidadedediversificação que surge com a conectividade. Háalguns anos, diversificar era al go equivalente a investir em umas poucas classes de títulos dentro deseu próprio país. Hoje, diversificar é ter na sua carteira títulos emitidos em países que possuam características distintas, apro-
Para os indivíduos, a conectividade também trouxegrandes impactos positivos. Um exemplo é o imenso portifólio de serviços bancários oferecidos por meios eletrônicos, facilitando significativamente o contato dos indivíduos com suas finanças. Saques em caixas eletrônicos, pagamentos via Internet e transferências el etrônicas são alguns dos serviços mais populares e que refletem os avanços na área.

Essa grande velocidade no acesso e na transmissão de informação torna o mundo dos negócios muito mais veitando os comportamentos distintos desses papéis para reduzir ou diluir os riscos dos investimentos sem que haja a possibilidade de comprometimento do retorno esperado.

Efeito-contágio. Um dos principais efeitos da conectividade sobre os mercados é certamente o que os especial istas chamam de efeito-contágio. Ou seja, quando uma al teração no comportamento de um mercado afeta 0 de outros. Geralmente, a principal forma de alteração de 
comportamento de mercado é a existência de crises. A magnitude do efeito de um contágio é de fácil constatação. Veja-se, por exemplo, os dados apresentados no Gráfico 1, que mostram o comportamento do Índice Bovespa na década de 1970, quando ocorreram duas crises internacionais, ambas relacionadas ao mercado de petróleo.

$\mathrm{Na}$ primeira crise, ocasionada pela guerra árabe-israelense de 1973, o preço do barril de petróleo subiu de US\$ 2,90 para US\$11,65, um aumento de mais de $300 \%$. Na ocasião, o Índice Bovespa caiu algo em torno de $20 \%$. A segunda crise do petróleo, ao contrário da primeira, teve múltiplas causas. 0 acidente nuclear da usina de Three Miles Island, nos EUA, colocou em xeque a geração de energia nuclear, ao mesmo tempo em que a derrubada do Xá Reza Pahlevi, no Irã, desorganizou o mercado de petróleo. A conseqüência foi um sal to no preço do barril de US\$ 13,00 para US\$ 34,00 . N esse caso, o Ibovespa cai pouco mais que $25 \%$.

Quando observamos o comportamento do mesmo Índice Bovespa na década de 1990, o que é ap resentado pelo Gráfico 2, notamos al gumas diferenças importantes em relação aos anos de 1970. Em primeiro lugar, observamos uma volatilidade muito maior, algo sem dúvida alguma explicado pela maior conectividade entre os diferentes mercados. A volatilidade anual, estimada em uma base mensal, atingiu 69\% na década de 1970 contra 120\% na década de 1990.

Em segundo lugar, podemos também perceber que as crises da década de 1990 têm efeitos mais desastro-

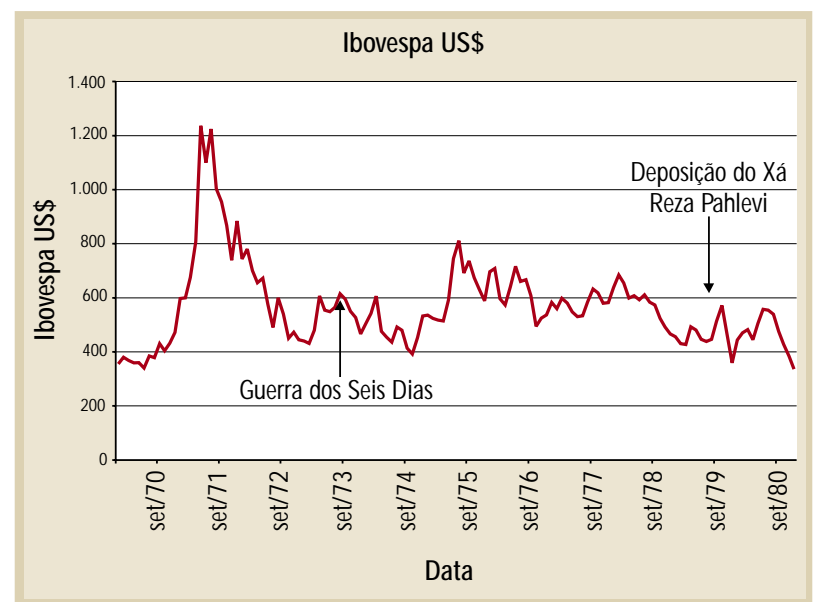

Gráfico 1 - Variação do Ibovespa no período de 1970-1980. sos, além de serem muito mais constantes. É claro que outras crises também aconteceram na década de 1970, além das duas do petróleo. A diferença é que seus efeitos ficaram restritos ao país de origem. Essa situação já não pode ser constatada no período de 1990 em diante, quando a conectividade dos mercados torna-se al go fortemente pronunciado.

Por exemplo, na primeira grande crise da década, a do México, deflagrada em dezembro de 1994, o Índice Bovespa caiu 35\% em um intervalo de três meses. Já na segunda crise, a da Ásia, que teve início em julho de 1997, o mesmo índice caiu 31\%, novamente em um intervalo curto de 3 meses. Por último, durante a crise da Rússia, em agosto de 1998, a queda foi de $40 \%$ em apenas um mês.

Origens do contági o. Mas qual é a origem do contágio? Há, na verdade, diversas explicações para sua existência. U ma primeira origem está ligada à força dos laços comerciais entre países. Isso pode ser observado, por exemplo, no episódio da crise da Ásia. Estudos indicam que o efeito foi maior entre os países que tinham maior densidade de trocas comerciais. Assim, uma crise em um país A, que é grande importador de produtos de $B$, provoca uma transferência de efeitos para este último, visto que os agentes econômicos esperam que as importações cessem ou diminuam. Nesse caso, B sofrerá rapidamente os efeitos da crise em A.

0 mesmo mecanismo pode ser constatado nas rela-

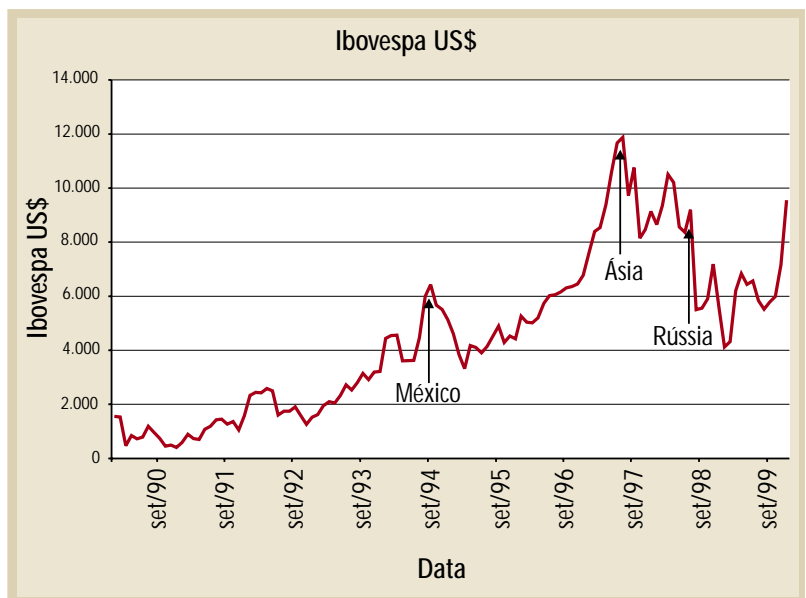

Gráfico 2 - Variação do Ibovespa no período de 1990-2000. 
ções financeiras em geral e em situações em que há similaridades macroeconômicas. Os investidores aprendem com os eventos passados e analisam países similares como sujeitos aos mesmos tipos de comportamentos diante de uma crise. Outro elemento importante nesse contexto é a presença de subsidiárias das mesmas empresas em diferentes países, o que aumenta o espectro do contágio.

Uma outra origem do contágio entre mercados é a intensidade do fluxo de informações. Tal fluxo pode ser dividido em dois momentos: em um primeiro, os investidores informados vendem títulos de países afetados pela crise para, por exemplo, atender a uma chamada de margem. Em um segundo momento, os investidores não informados interpretam essa mesma venda como sinal de baixos retornos e então passam a disseminar o pânico.

No entanto, é consenso que o elemento mais importante para a disseminação de uma crise é o comportamento dos investidores. A diversificação das carteiras de investimentos envolve, hoje, a compra de títulos de diferentes países. Desse modo, um fundo de investimentos sediado em Londres possui títulos de países da América Latina, Ásia e muitos outros. No início de uma crise em um país emergente, os gestores desse fundo buscarão reduzir sua exposição nesse tipo de país, temendo um contágio.

Como conseqüência, inicia-se um movimento de venda de títulos de países emergentes por parte de todos os fundos similares a este, instalando-se, desse modo, um contágio entre as diferentes economias. 0 Brasil é, tipica-

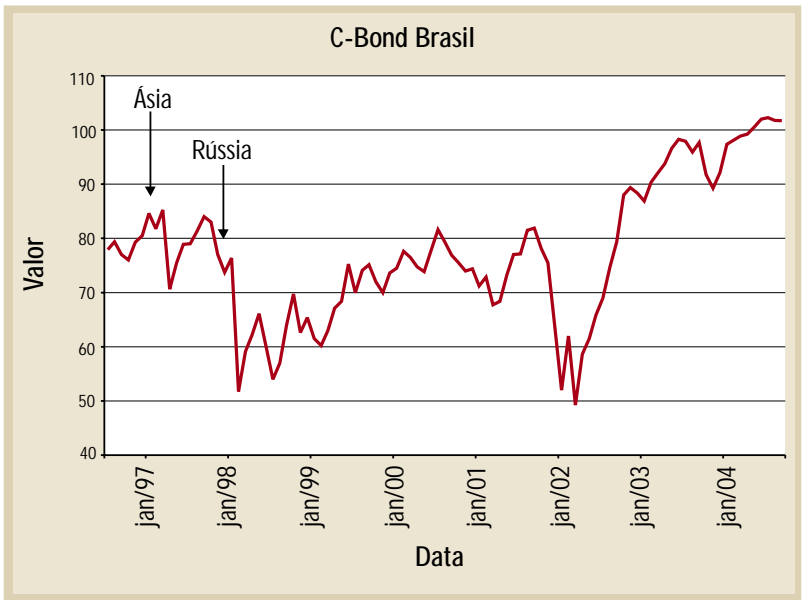

Gráfico 3 - Variação do C-Bond Brasil no período de janeiro de 1997 a janeiro de 2005. mente, um dos países que mais sofre nesses momentos. A razão é simples: tanto nossos títulos de dívida externa como nossa bolsa de valores possuem boa liquidez perante os títulos de outros países emergentes. Como resultado, nossos títulos são os primeiros a serem colocados à venda e, logo, os que mais sofrem. 0 gráfico 3 mostra o comportamento do C-Bond, títulos da dívida externa brasil eira mais negociados no mercado internacional.

O bserve que os efeitos da crise da Ásia e da Rússia são nítidos. Esse "efeito Brasil" pode ser constatado ao observarmos o comportamento da volatilidade dos diferentes mercados em períodos pré e posteriores a crise (ver Tabela). N ote, a partir da tabela apresentada, os impactos sobre os títulos de dívida externa dos países emergentes das diversas crises recentes, como as daÁsia, Rússia, Nasdaq, Argentina edo World Trade Center. Podemos constatar, pela tabela, que, ao mesmo tempo em que o Brasil possui uma volatilidade relativamente baixa nos períodos pré-crises, ele exibe a maior volatilidade, entre os países emergentes, nos períodos póscrises. A razão é a maior liquidez de nossos títulos.

Por fim, umaúltima origem para o efeito-contágio está ligada a variáveis internas. Por exemplo, se continuarmos a observar o comportamento do C-Bond em 2002, no gráfico 3, vemos uma grande queda em seu valor, comparável apenas à crise russa. A origem dessa queda é interna, coincidindo com a ascensão do então candidato Lula nas pesquisas e com a difusão de informações altamente preocupantes sobre a futura condução da economia.

Conseqüências do contágio. Para finalizar, analisamos as principais conseqüências do efeito contágio. Em particular, apresentamos essas conseqüências sobre a economia, as empresas e os indivíduos.

No que diz respeito à economia, se um país sofre 0 contágio de uma crise em um outro país, os capitais vão procurar outros portos seguros. Isso ocorre porque os capitais internacionais são guiados pela relação retorno versus risco. Como resultado, o país que sofreu a evasão de capitais assiste a uma diminuição em seus índices de investimento. Outro resultado é a desvalorização da moeda local, pois todos querem retirar suas divisas desse país.

$N$ ão é necessária a existência de crises agudas para se observar efeitos semel hantes. Veja-se, por exemplo, a si- 
tuação do déficit norte-americano. Depois de anos de controle sob a administração Clinton, as expectativas do mercado são de el evação desse déficit. N esse cenário, os agentes econômicos esperam elevação das taxas de juros futuras em virtude das pressões que o tesouro norte-americano exercerá para cobrir o referido déficit. A expectativa de maiores taxas reflete-se no presente ao diminuir a liquidez do mercado internacional. Menor liquidez significa menores investimentos em países emergentes.

Sobre as empresas, o principal efeito da conectividade dos mercados é observado na volatilidade dos custos e receitas. São raros os empreendimentos que podem hoje prescindir de insumos importados. Desse modo, variações nas taxas de câmbio afetam diretamente os custos das empresas. E a taxa de câmbio tem maior volatilidade em função da maior conectividade entre os mercados. As receitas também são afetadas pelas variações no câmbio, diretamente no caso das empresas exportadoras e indiretamente para toda a cadeia associada ao complexo exportador.

No que diz respeito aos indivíduos, pode-se também encontrar al guns efeitos da conectividade. 0 primeiro emais imediato é sobre os investimentos. Uma volatilidade maior é facilmente constatável. E volatilidade maior significa maior risco, o que se observa mesmo nos investimentos tradicionalmente mais seguros, como os de renda fixa. A redução do risco é mais difícil, haja vista que, nas crises, as correlações entre os investimentos tendem a 1 , ou seja, em uma crise as estratégias de diversificação têm pouco efeito já que todos os ativos tendem a um comportamento similar. Em prazos um pouco mais longos, observa-se que a renda dos indivíduos também é afetada pela conectividade, pois o nível de investimentos do país é afetado, gerando uma onda de reações, como a baixa oferta de empregos e, conseqüentemente, a retração da renda das famílias.

Para finalizar este artigo, cumpre mencionar uma conseqüência especialmente positiva da conectividade, em particular sobre o campo de pesquisas em Finanças. A imensa facilidade e 0 baixo custo para 0 armazenamento de dados nos permitem hoje analisar de forma profunda as diferentes economias do globo, fato impensável há alguns anos. Desse modo, temos um maior conhecimento das relações existentes entre os mercados, inclusive das dinâmicas destacadas neste artigo referentes à crescente conectividade. Com isso, aumentam-se as chances de atuar sobre essas dinâmicas de forma mais rápida e eficiente, minimizando, tanto quanto seja possível, suas conseqüências desastrosas.

William Eid Júnior

Prof. do Departamento de Contabilidade, Finanças e Controle da FGV-EAESP

Doutor em Administração Financeira pela FGV-EAESP

E-mail: weid@fgvsp.br

\section{Tabela - Índice de volatilidade média dos mercados em períodos de crise e pré-crise.}

\begin{tabular}{|l|c|c|c|c|c|c|c|}
\hline \multicolumn{7}{|c|}{ VOLATILIDADE MÉDIA EM PERIODOS DE CRISE } \\
\hline & BRASIL & TURQUIA & HONG KONG & MÉXICO & ARGENTINA & CHILE & RUSSIA \\
\hline Ásia & $56,14 \%$ & $44,14 \%$ & $46,99 \%$ & $31,95 \%$ & $35,85 \%$ & $16,47 \%$ & $27,82 \%$ \\
\hline Rússia & $64,17 \%$ & $64,02 \%$ & $37,74 \%$ & $36,84 \%$ & $45,45 \%$ & $28,43 \%$ & $98,56 \%$ \\
\hline Nasdaq & $34,56 \%$ & $53,30 \%$ & $33,94 \%$ & $36,93 \%$ & $30,13 \%$ & $19,23 \%$ & $55,50 \%$ \\
\hline Argentina & $36,19 \%$ & $66,45 \%$ & $30,08 \%$ & $23,70 \%$ & $40,44 \%$ & $11,49 \%$ & $28,08 \%$ \\
\hline WTC & $39,96 \%$ & $48,50 \%$ & $32,32 \%$ & $23,20 \%$ & $53,69 \%$ & $17,28 \%$ & $35,97 \%$ \\
\hline \multicolumn{70}{|c|}{ VOLATILIDADE MÉDIA EM PERIODOS DE PRÉ-CRISE } \\
\hline Ásia & $23,73 \%$ & $36,98 \%$ & $15,87 \%$ & $19,17 \%$ & $22,57 \%$ & $13,94 \%$ & $42,04 \%$ \\
\hline Rússia & $25,79 \%$ & $50,01 \%$ & $37,45 \%$ & $20,99 \%$ & $23,36 \%$ & $18,82 \%$ & $44,21 \%$ \\
\hline Nasdaq & $26,97 \%$ & $51,53 \%$ & $25,14 \%$ & $27,97 \%$ & $30,82 \%$ & $19,12 \%$ & $54,62 \%$ \\
\hline Argentina & $29,83 \%$ & $59,48 \%$ & $25,70 \%$ & $29,77 \%$ & $29,29 \%$ & $12,17 \%$ & $45,62 \%$ \\
\hline WTC & $23,56 \%$ & $53,63 \%$ & $19,71 \%$ & $19,08 \%$ & $40,18 \%$ & $10,67 \%$ & $25,76 \%$ \\
\hline
\end{tabular}

Fonte: Tucci, Renato Eid. Analisando a Evolução do Efeito-Contágio em Mercados Emergentes - FEA/IME - USP - 2005. 